\title{
Regeneration and the Plant We have Inside
}

Valeria Cernaro ${ }^{1}$, Valentina Donato ${ }^{1}$, Adolfo Romeo ${ }^{1}$, Antonio Lacquaniti ${ }^{2}$, Michele Buemi ${ }^{{ }^{*}}$

${ }^{1}$ Chair of Nephrology, Department of Clinical and Experimental Medicine, University of Messina, Messina, Italy

${ }^{2}$ Division of Nephrology, Mediterranean Institute for Transplantation and Advanced Specialized Therapies, University of Pittsburgh Medical Center in Italy, Palermo, Italy *Corresponding author: Cernaro V, Chair of Nephrology, Department of Clinical and Experimental Medicine, University of Messina, Messina, Italy, Tel: +39.090.2212396; Fax: +39.090.2935162; E-mail: buemim@unime.it

Rec date: Aug 19, 2014, Acc date: Oct 06, 2014, Pub date: Oct 15, 2014

Copyright: ( 2014 Cernaro V, et al., This is an open-access article distributed under the terms of the Creative Commons Attribution License, which permits unrestricted use, distribution, and reproduction in any medium, provided the original author and source are credited.

\begin{abstract}
Regeneration is a process that occurs in simple organisms and allows them to rebuild entire parts of the body following an injury. This process is subject to restrictions as progressive as going from the simplest organisms to more complex ones, such as humans, where regeneration is limited to a few examples and an injury is followed in most cases by fibrosis. The mechanisms underlying the different regeneration entity among the various species are still unclear. An example of regeneration is given by plants, whose development and growth are regulated by a class of phytohormones called "Auxin". The principal auxin produced by the plants is indole-3-acetic acid. Surprisingly, this substance has also been found in humans, where it is considered one of uremic toxins. Why auxin not associated with regenerative abilities in humans as is occurs in plants? And yet, why should a plant hormone is found in an animal organism? In 2011, the first evidence of symbiosis was assessed between a green alga and a vertebrate, the spotted salamander. Moreover in fishes, cells called "rodlet cells" are present and their nature is still uncertain, since they have a cell wall that is typical of vegetable organisms. As both salamanders and fishes can regenerate parts of their body after injury, we wonder if these different aspects, apparently independent of each other, have not actually common points. Auxin may be the connecting link, both for its functions in plants and because there are examples of symbiosis between the animal and plant kingdoms.
\end{abstract}

Keywords: Auxin; Fibrosis; Regeneration

\section{Introduction}

Regeneration is a process that occurs in simple organisms and allows them to rebuild whole parts of the body following an injury. An example is the Hydra, one of the simplest diploblasts that is able to regenerate its head after amputation thanks to the presence of several undifferentiated cells that are constantly in mitosis [1]. Interestingly, head regeneration occurs through different paths depending on the level of amputation suggesting that the process of repair is considerably influenced by the homeostatic background present at that time [2]. The triploblast Planaria (Freshwater planarians, Plathelminthes) regenerates missing parts of its body because it is endowed with undifferentiated cells, called neoblasts, which actively proliferate. These are pluripotent adult somatic stem cells that give rise to all types of somatic cells as well as germline cells [3].

The most extensive regenerative capacity in adult vertebrates can be found in salamanders. They are more complex triploblasts and, under normal conditions, do not possess undifferentiated cells. After amputation of a limb, stump cells are dedifferentiated and proliferate, forming a "blastema of regeneration" which reconstructs the missing limb with the same characteristics and the same size of that amputated, as if there was a sort of memory that is stored and then used in the regenerative process [4]. Therefore, the regeneration undergoes restrictions as progressive as going from the simplest organisms to more complex ones, such as humans, where regeneration is limited to a few examples (angiogenesis [5,6] and regeneration of epidermis [7], gastric and intestinal epithelium [8], fingertip [9] and hematopoietic cells [10]). In more complex beings, an injury is followed in most cases by fibrosis, a pathophysiological process characterized by infiltration and proliferation of mesenchymal cells in interstitial space which occurs for repairing epithelial damage leading to the formation of granulation tissue and then to scarring [11]. Thus, fibrosis allows "turning off" the inflammation and repairing the injury, but the price to be paid is the replacement of parenchymal cells with fibrotic tissue, resulting in a loss of function of the damaged organ. In some ways, however, fibrosis can be considered a positive event: it could be a product of evolution in order to prevent a regenerative process not adequately controlled, avoiding the formation of a tumour. This could explain why regeneration disappeared almost completely in superior organisms and humans, in a sort of "negative selection" [12].

How does this happen? What are the molecular mechanisms that allow and regulate the regeneration in the simplest organisms and those that limit it in humans?

An obvious example of regeneration is given by plants. It is known that the hormone responsible for the development and growth of plants is the Auxin. The term "auxin" actually refers to a class of phytohormones which are essential for growth and development of plants. The principal auxin produced by the plants is indole-3-acetic acid; it regulates the division, extension and differentiation of the cells, and plays a key role in tropisms, root initiation, apical dominance, and senescence [13]. Indole-3-acetic acid can be synthesized de novo from the precursor represented by the amino acid tryptophan or through a tryptophan-independent pathway [14]. The first is the main pathway, because it is essential for embryogenesis, seedling growth, flower development, vascular pattern formation and other development processes. It has been fully defined only recently: tryptophan is first converted to indole-3-pyruvate by TAA1/TAR (Tryptophan Aminotransferase of Arabidopsis1/Tryptophan AminotransferaseRelated) of aminotransferases family; subsequently indole-3-pyruvate 
is transformed into indole-3-acetic acid by the YUC (YUCCA) of the flavin monooxygenase family $[15,16]$. The molecular components and the physiological functions of tryptophan-independent pathway are not yet known [17].

Auxin is involved not only in the development and growth of plants, but also in the phenomenon of phototropism, that allows plants to align their photosynthetic tissues with the incoming light. The direction of the incident light is perceived by protein kinase photoreceptors belonging to the phototropins family; this leads to the formation of an auxin gradient through the hypocotyl resulting in the directional, asymmetric plant growth [18].

As well as in plant tissues, indole-3-acetic acid biosynthesis occurs in plant-associated bacteria, giving them the ability to influence plant growth [13].

Surprisingly, this substance has been detected also in humans [19]. It is unknown where and why it is produced, but indole-3-acetic acid is considered one of uremic toxins, along with other organic acids. In particular, it belongs to the group of the protein-bound molecules [20]. Developing a HPLC technique for the simultaneous determination of different uremic solutes of clinical interest in biological fluids, Calaf and collaborators have observed that serum concentration of indole-3-acetic acid increases going from healthy subjects $(2.12 \mu \mathrm{M})$ to patients with stage $3-5$ chronic kidney disease not on haemodialysis $(3.21 \mu \mathrm{M})$ to haemodialysis patients $(5.9 \mu \mathrm{M})$ [21]. Moreover, indole-3-acetic acid seems to contribute to thrombotic risk induced by uremic milieu, as recently demonstratedin a model of human vascular smooth muscle cells pre-treated with serum obtained from dialysed patients and exposed to a blood flow similar to the coronary one. Uremic serum significantly increased expression and activity of tissue factor (TF) in smooth muscle cells favouring stent thrombosis. The same effects were reproduced after the addition of high concentrations of isolated uremic solutes (indole-3-acetic acid, indoxyl sulfate or uric acid) [22].

Why is auxin not associated with regenerative abilities in humans as it does in plants? Maybe is its mechanism of action different in the two types of organisms? And yet, why should a plant hormone be found in an animal organism? It could be supposed the presence of auxin in animals to be due to cases of symbiosis, namely the association, persisting over time, of two organisms belonging to different species with reciprocal benefit [23]. The first evidence of symbiosis was assessed in 2011, between a green alga (Oophila amblystomatis) and a vertebrate, the spotted salamander (Ambystoma maculatus), both in embryos and in adult organisms. In particular, it has been observed that early embryonic egg capsules included encysted algal cells on the inner capsule wall, and algal $18 \mathrm{~S}$ rDNA was amplified from adult reproductive tracts, leading to the hypothesis that an oviductal transmission of algae from one salamander generation to the next occurs [24] (Figure 1). Until that time, it was thought that these symbiotic relationships existed only in invertebrates or between microorganisms and higher organisms such as plants and animals [25].

This finding raises important questions about the phyloontogenetic meaning of "cohabitation." It has been demonstrated that there is a mutual advantage: algae use nitrogen released by the embryonic metabolism, while embryos benefit from the oxygen increase due to the process of photosynthesis. However, are these advantages limited to this exchange of metabolites or do they involve other aspects of embryonic development? What is the role of the persistence of this symbiosis in adult organism?

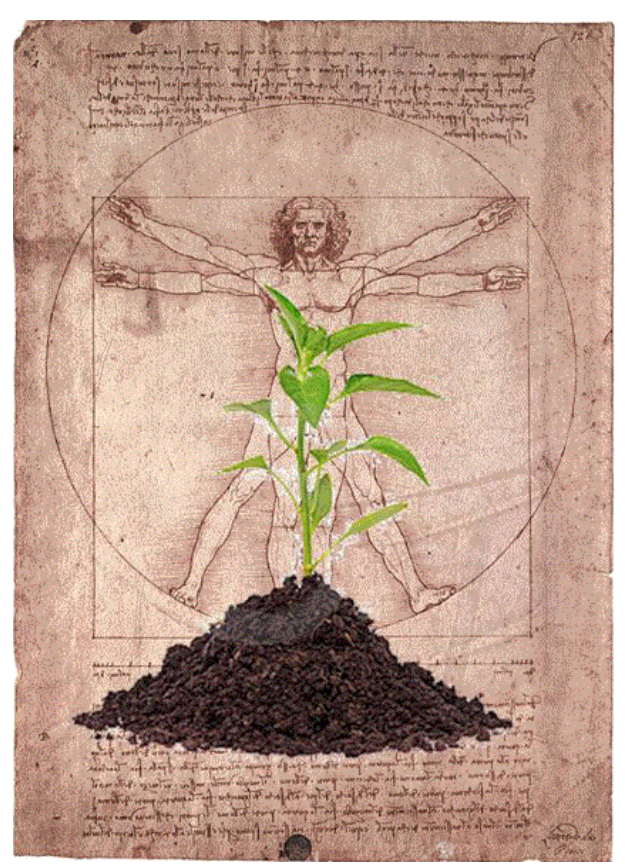

Figure 1: Schematic representation of the first symbiotic relationship identified between a green alga and a vertebrate. Encysted algal cells of Oophila amblystomatis are present on the inner capsule wall of the early embryonic egg and invade the blastopore of spotted salamander (Ambystoma maculatus).

This finding raises important questions about the phyloontogenetic meaning of "cohabitation." It has been demonstrated that there is a mutual advantage: algae use nitrogen released by the embryonic metabolism, while embryos benefit from the oxygen increase due to the process of photosynthesis. However, are these advantages limited to this exchange of metabolites or do they involve other aspects of embryonic development? What is the role of the persistence of this symbiosis in adult organism? Does the presence of plant cells in vertebrates only interest salamanders or also characterize other animal species? Algae share the same natural habitat of amphibians and other aquatic organisms. In the course of evolution algae may have also established symbiotic relationships with other species, such as fishes. Although speculative, this hypothesis cannot be beforehand excluded given the presence in fishes of cells called "rodlet cells" [26], whose nature is still uncertain. The most peculiar and enigmatic feature of these cells is that they have a cell wall that is not found in animal cells, but it is typical of vegetable organisms.

Furthermore, as widely demonstrated, fishes, similarly to salamanders, are able to regenerate parts of their body after injury or amputation [5,27].

It is therefore natural to wonder whether these different aspects, apparently independent of each other, have not actually common points.

Auxin may be the connecting link between the various elements above described, both for its functions in plants and because there are examples of symbiosis between the animal and plant kingdoms. In 
other words, auxin might be present in animals owing to symbiotic interactions with plants and accordingly, it could represent the factor responsible for regeneration in those organisms, such as fishes and salamanders, provided with the ability to regenerate damaged organs and tissues.

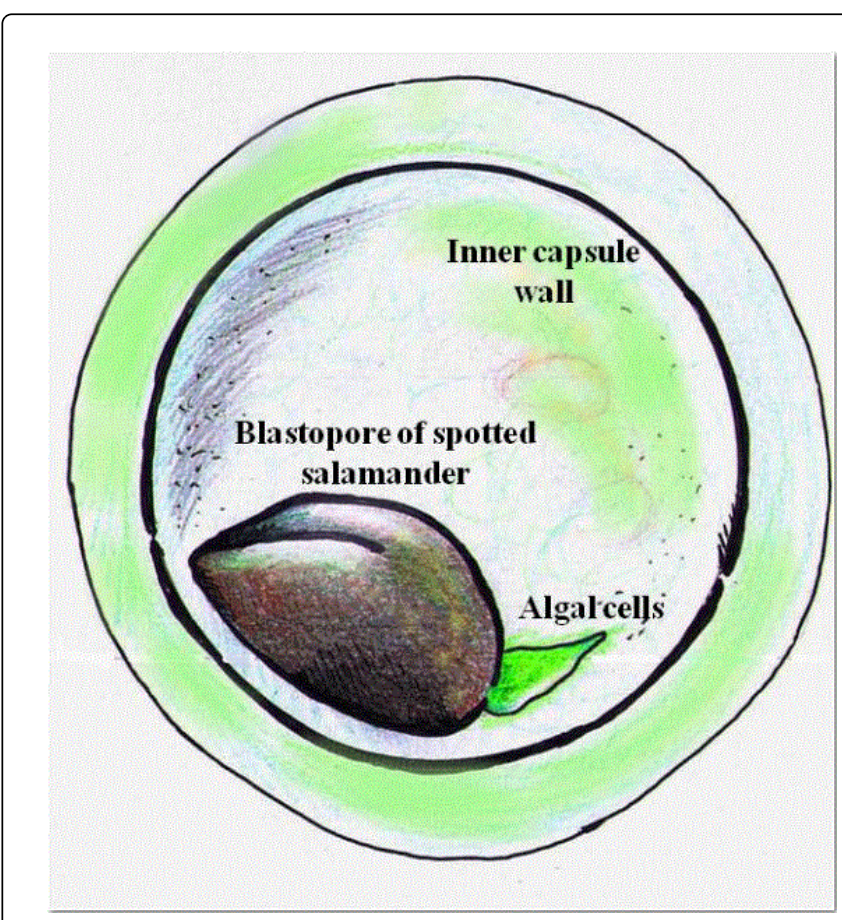

Figure 2: A plant hormone, called auxin, is present in humans.

These considerations highlight regeneration is still poorly understood, particularly with regard to the differences of expression and entities among the various animal species. The presence of auxin also in complex animal organisms, including humans, poses questionsmaybe still far from being answered, but fascinating and challenging for scientists (Figure 2). Research, in fact, is increasingly going towards the study of the mechanisms of regeneration, because these could provide an opportunityfor healing of chronic diseases. We can actually try to slow the natural progression of chronic diseases, since no effective therapeutic weapons against fibrosis are available [28].

\section{References}

1. Bergmann A, Steller H (2010) Apoptosis, stem cells, and tissue regeneration. Sci Signal 3: re8.

2. Galliot B, Ghila L (2010) Cell plasticity in homeostasis and regeneration. Mol Reprod Dev 77: 837-855.

3. Shibata N, Rouhana L, Agata K (2010) Cellular and molecular dissection of pluripotent adult somatic stem cells in planarians. Dev Growth Differ 52: $27-41$.

4. Garza-Garcia AA, Driscoll PC, Brockes JP (2010) Evidence for the local evolution of mechanisms underlying limb regeneration in salamanders. Integr Comp Biol 50: 528-535.

5. Buemi M, Lacquaniti A, Maricchiolo G, Bolignano D, Campo S, et al (2009) Regenerative medicine: does Erythropoietin have a role?. Curr Pharm Des 15: 2026-2036.

6. Buemi M, Campo S, Cernaro V, Donato V, Lacquaniti A (2011) Erythropoietin and the truths of science. J Nephrol 24: 564-568.
7. Plikus MV, Gay DL, Treffeisen E, Wang A, Supapannachart RJ, et al. (2012) Epithelial stem cells and implications for wound repair. Semin Cell Dev Biol 23: 946-953.

8. Sémont A, Mouiseddine M, François A, Demarquay C, Mathieu N, et al. (2010) Mesenchymal stem cells improve small intestinal integrity through regulation of endogenous epithelial cell homeostasis. Cell Death Differ 17: 952-961.

9. Muneoka K, Allan CH, Yang X, Lee J, Han M (2008) Mammalian regeneration and regenerative medicine. Birth Defects Res C Embryo Today 84: 265-280.

10. Buemi M, Lacquaniti A, Bolignano D, Cernaro V, Campo S, et al. (2009) Down with the erythropoietin. Long live the erythropoietin!. Curr Drug Targets 10: 1028-1032.

11. Doi S, Zou Y, Togao O, Pastor JV, John GB, et al (2011) Klotho inhibits transforming growth factor-betal (TGF-beta1) signaling and suppresses renal fibrosis and cancer metastasis in mice. J Biol Chem 286(10): 8655-8665.

12. Cernaro V, Lacquaniti A, Donato V, Fazio MR, Buemi A, et al (2012) Fibrosis, regeneration and cancer: what is the link? Nephrol Dial Transplant 27(1): 21-27.

13. Vande Broek A, Gysegom P, Ona O, Hendrickx N, Prinsen E, et al. (2005) Transcriptional analysis of the Azospirillum brasilense indole-3pyruvate decarboxylase gene and identification of a cis-acting sequence involved in auxin responsive expression. Mol Plant Microbe Interact 18: 311-323.

14. Kim JI, Baek D, Park HC, Chun HJ, Oh DH, et al. (2013) Overexpression of Arabidopsis YUCCA6 in potato results in high-auxin developmental phenotypes and enhanced resistance to water deficit. Mol Plant 6: 337-349.

15. Stepanova AN, Yun J, Robles LM, Novak O, He W, et al. (2011) The Arabidopsis YUCCA1 flavin monooxygenase functions in the indole-3pyruvic acid branch of auxin biosynthesis. Plant Cell 23: 3961-3973.

16. Hofmann NR (2011) YUC and TAA1/TAR proteins function in the same pathway for auxin biosynthesis. Plant Cell 23: 3869.

17. Zhao Y (2012) Auxin biosynthesis: a simple two-step pathway converts tryptophan to indole-3-acetic acid in plants. Mol Plant 5: 334-338.

18. Hohm T, Preuten T, Fankhauser C (2013) Phototropism: translating light into directional growth. Am J Bot 100: 47-59.

19. Gondouin B, Cerini C, Dou L, Sallée M, Duval-Sabatier A, et al (2013) Indolic uremic solutes increase tissue factor production in endothelial cells by the aryl hydrocarbon receptor pathway. Kidney Int 84(4): 733-744.

20. Basile C, Libutti P, Di Turo AL, Casino FG, Vernaglione L, et al. (2011) Removal of uraemic retention solutes in standard bicarbonate haemodialysis and long-hour slow-flow bicarbonate haemodialysis. Nephrol Dial Transplant 26(4): 1296-1303.

21. Calaf R, Cerini C, Génovésio C, Verhaeghe P, Jourde-Chiche N, et al. (2011) Determination of uremic solutes in biological fluids of chronic kidney disease patients by HPLC assay. J Chromatogr B Analyt Technol Biomed Life Sci 879: 2281-2286.

22. Chitalia VC, Shivanna S, Martorell J, Balcells M, Bosch I, et al. (2013) Uremic serum and solutes increase post-vascular interventional thrombotic risk through altered stability of smooth muscle cell tissue factor. Circulation 127: 365-376.

23. Asgari S (2014) Epigenetic modifications underlying symbiont-host interactions. Adv Genet 86: 253-276.

24. Kerney R, Kim E, Hangarter RP, Heiss AA, Bishop CD, et al. (2011) Intracellular invasion of green algae in a salamander host. Proc Natl Acad Sci U S A 108: 6497-6502.

25. Furukawa S, Watanabe T, Toyama H, Morinaga Y (2013) Significance of microbial symbiotic coexistence in traditional fermentation. J Biosci Bioeng 116: 533-539.

26. Siderits D, Bielek E (2009) Rodlet cells in the thymus of the zebrafish Danio rerio (Hamilton, 1822). Fish Shellfish Immunol 27: 539-548. 
Citation: Cernaro V, Donato V, Romeo A, Lacquaniti A, Buemi M (2014) Regeneration and the Plant We have Inside. J Mol Genet Med 8: 137. doi:10.4172/1747-0862.1000137

Page 4 of 4

27. Buemi M, Lacquaniti A, Bolignano D, Maricchiolo G, Favaloro A, et al. (2009) The erythropoietin and regenerative medicine: a lesson from fish. Eur J Clin Invest 39: 993-999.
28. Cernaro V, Trifirò G, Lorenzano G, Lucisano S, Buemi M, et al. (2014) New therapeutic strategies under development to halt the progression of renal failure. Expert Opin Investig Drugs 23: 693-709. 